\title{
The Effect of Current Family Situation on Slow Walking Speed at Old Age
}

\author{
Gabriele Doblhammer, Steffen Peters, Debora Rizzuto \\ and Anna-Karin Welmer
}

\section{Introduction}

Walking (or gait) speed is an important measure of health and frailty among the elderly (Bergman et al. 2007; Studenski et al. 2011; Cooper et al. 2014). Slow walking speed is related to increased mortality (Studenski et al. 2011) and to an increased risk of dementia (Welmer et al. 2014). Together with other deficits in physical function it predicts falls, especially in people with global cognitive impairment (Welmer et al. 2016). The relationship between fast walking speed and health is rooted in more healthy behaviors, lower cardiovascular risk factors, and lower levels of inflammatory markers (Elbaz et al. 2013). Furthermore, slow walking speed, is strongly related to slow processing speed, an early sign of deteriorating cognitive functioning (Welmer et al. 2014). Given its strong predictive power in terms of health it is advantageous in that it can be easily assessed by non-professionals (Atkinson et al. 2007). Turning to the demographic and social correlates of walking speed, a gender difference has been observed, with men

\footnotetext{
G. Doblhammer ( $\bowtie)$

German Center for Neurodegenerative Disease (DZNE), Bonn, Germany

e-mail: gabriele.doblhammer@uni-rostock.de

S. Peters

Rostock Center for the Study of Demographic Change, Rostock, Germany

e-mail: steffen.peters@uni-rostock.de

D. Rizzuto · A.-K. Welmer

Department of Neurobiology, Care Sciences and Society, Karolinska Institutet, Aging Research Center, Stockholm, Sweden

e-mail: Debora.Rizzuto@ki.se
}

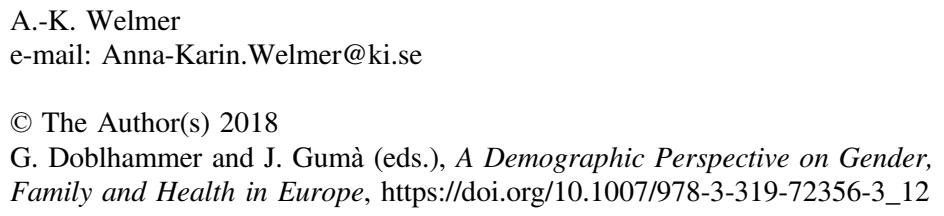


outperforming women particularly at old ages (Weber 2016; also see the chapter of Oksuzyan et al.). Recent studies (Weber 2016; Welmer et al. 2013) have demonstrated a strong social gradient in walking speed, with the highly educated men and women always walking faster than their less educated counterparts. This advantage, however, diminishes at higher ages. Little is known about the relationship between walking speed and family situation, another important determinant of health at old age. This study thus sets out to provide a longitudinal perspective of the predictive power of the current family situation, measured in terms of partnership and parenthood, on slow walking speed.

This book contains several chapters which analyze myriad family effects and in the following we refer to them. Partnership and parenthood have strong positive and negative effects on health over the whole life course (Hank and Steinbach). The European comparative study by Doblhammer and Gumà shows that during mid-life the differences in health by family status were larger among women than among men; as also confirmed by the studies of Georges, Kreft and Doblhammer, and Ennser-Buber and Hanappi. Furthermore, the differences were related to life-style factors such as smoking, at-risk alcohol consumption, unhealthy diet, and physical exercise as demonstrated by the study of von der Lippe and Rattay. At old age there is a general consensus that it is particularly men who benefit from living with a partner and being married (Hank and Steinbach), while the effects for elderly women are less clear. There seem to be strong positive and negative effects of parenthood on health for women, less so for men, independent of the particular characteristics of their partnership biography (Tomassini, Di Gessa and Egidi).

In the following we will briefly summarize these findings, as these provide an important background for our own study, first turning to partnership, then to parenthood, and finally discussing possible pathways of these associations.

\section{Partnership}

While the positive effects of partnership and the selection into partnership have been widely documented (particularly those of marriage), the negative effects have been investigated only recently, with the exception of changes in partnership status such as divorce or widowhood (Hank and Steinbach). Such changes have been shown to have gendered effects, e.g. divorce leads to comparatively better health among men and worse health among women. Marital biographies seem to have a stronger impact on slowly developing health conditions such as chronic disease and functional limitations, while current partnership status seems to impact strongly on mental health. The latter seems to be particularly dependent on satisfaction with the partnership and its reciprocity (Hank and Steinbach). 


\section{Parenthood}

A series of studies have shown that parents of two to three children experience the best health among the elderly, particularly among women, less so among men, independent of the definition of health (Hank and Steinbach; Tomassini, Di Gessa, and Egidi). However, these studies have also pointed out that for women a high number of children results in worse physical and mental health and in higher mortality from cardiovascular disease, and, for both genders, early parenthood appears to be detrimental for later physical health outcomes. A high number of children and early parenthood may be related to economic strain, worse partnership quality, and role overload for (single) parents. The effects of early motherhood depended on the social environment, and its negative effect was less strong in societies where early fertility was more common and socially accepted. The health differences according to number of children were independent of the partnership and fertility biography. Whether childlessness has a negative effect on health at old age is still unclear, as studies come to mixed conclusions. Tomassini, Di Gessa and Egidi find no health disadvantage for the childless in Italy, yet Hank and Steinbach reviewed studies which showed a clear disadvantage in various European countries. On the other hand, they also point out that there is evidence that childless men and women experience less depressive symptoms than parents.

\section{Pathways}

Most studies stressed that children and a partner are an important resource at old age in terms of providing care, reducing psychosocial stress, and increasing overall well-being (Hank and Steinbach; Tomassini, Di Gessa, and Egidi). They also pointed out that being a parent at midlife may have positive effects on health behavior (von der Lippe and Rattay). Health detrimental behaviours, such as smoking and at-risk alcohol consumption, seem to be more strongly associated with partnership and parenthood than with poor diet and physical inactivity. The risk of a relapse after quitting smoking is higher if the partner also smokes, while the presence of young children reduces the risk of smoking for women. Single men and women are more likely to have at-risk alcohol consumption, thus the transition to marriage and parenthood has been suggested as a constraint on drinking behaviour. The extent of physical activity is very different in men and women, and parenthood seems to have more effect on the physical activity of mothers than of fathers. Whether the extent of physical activity of mothers is compromised by their children is, however, still unresolved, with some studies finding a decline and others an increase (von der Lippe and Rattay).

Social status explains some of the relationship between family situation and health but by far not all (Doblhammer and Gumà). In this context, an important 
pathway is related to financial difficulties, mainly among single mothers and mothers living in consensual unions and stepfamilies (Doblhammer and Gumà, Buber-Ennser and Hanappi).

\section{Reverse Causation}

Studies dealing with the relationship between health and family status must always account for the possibility of health selection into partnership and parenthood (Hank and Steinbach). Thus, one always needs to account for reverse causation, meaning that an individual's poor health could lead to living single, to losing the partner due to divorce or widowhood, or to staying childless. This becomes even more important at old age when the partners tend to become more equal in their health despite an increasing variability in health profiles with age. Thus, the family status of an individual may to some extent be determined by the health of the partner and the "contagion" or poor health among partners (Giannantoni and Egidi). In our own analysis we try to account for such health selection effects by introducing a time dimension between the characteristics of an individual and the outcome variable walking speed. In other words, we use the characteristics from a previous wave to predict the walking speed in a follow-up wave.

\section{Aims and Hypotheses}

Considering all of the various negative and positive effects that partnership and parenthood can have, gives rise to the question of the net-effect of the current family situation at old age. If the current family situation primarily reflects the availability of support, a higher number of family members should result in better health. On the contrary, if possible positive and negative influences of a partner and children prevail at old age, the number of family members is not necessarily positively correlated with good health. In addition, the relationship may be gender specific. Over the whole life course the distribution of paid and unpaid work within households is gender specific (see the chapter by Oláh et al.), which may influence the health behaviour. Also the values and norms in terms of health behaviour that govern the role models for mothers and fathers are gender specific (see the chapter by von der Lippe and Rattay). At old age, women are the main familial care providers to their partners (Revenson et al. 2015) and are thus exposed to the negative effects of the caregiver burden to a larger extent than men. At the same time, men are mainly at the receiving end of care provision due to their lower life expectancy.

Despite the presence of positive and negative effects of partnership and parenthood on health over the whole life course, we assumed that the availability of possible familial resources of help is the decisive factor at old age. Thus, we 
hypothesized that those living with a partner and who had had children would have the best walking performance and would maintain it for a longer period, due to the health selection into partnership and parenthood as well as due to protective effects. On the contrary, the childless without a partner would fare worst. The other groups (with either partner or children) would fare intermediately. This should be true for both genders, yet even more so for men because women are the main care providers at old age and thus are at the giving rather than the receiving end of help.

\section{Study Population}

Study population: We used the Swedish National Study on Aging and Care in Kungsholmen (SNAC-K) — a part of Stockholm (Lagergren et al. 2004). The sample included persons aged 60 years and older, living in private or institutional households. The sample was randomly selected by specific age cohorts. To reduce attrition during the follow-up, eleven age cohorts were chosen with different intervals: six-year intervals in the younger age groups (60-78 years old), and three-year intervals in the older groups ( $>78$ years old). The two youngest and the four oldest age groups were oversampled. The baseline survey was conducted in 2001-2004 and follow-ups were performed every 6 years for younger cohorts (6078 years) and every 3 years for older cohorts ( $78+$ years). Data was collected at the research center or at participants' homes through interviews, clinical examinations, and testing by trained staff. The following Fig. 1 shows the structure of the study population and the final analysis sample of our study.

A total of 5111 people were initially selected for participation; of those 200 died before start of the study, 262 had no contact information, 32 had moved, 23 did not speak Swedish, and 4 were deaf. Of the remaining 4590 people, $3363(73.3 \%)$ participated in the baseline examination. At baseline (BL), the study population (Fig. 1, top) of 1782 respondents below age 78 (young), and 1581 persons aged 78 years and above (old). Of the young, 157 died before the six-year follow-up (6YFU) and 229 had either moved or refused to participate any more, resulting in 1396 respondents, all of whom have information at baseline and in the follow-up. Of the old, 437 died and 152 dropped out due to other reasons. Thus, 992 persons were re-examined at the first follow-up after three years (3YFU). Of these, 662 also participated in the 6YFU, as 249 people had died between the $3 \mathrm{YFU}$ and the 6YFU and another 81 persons didn't participate for other reasons.

To arrive at the analytical sample (Fig. 1, bottom), we excluded all participants who were unable to walk at the baseline examination or who did not participate in any of the follow ups. This resulted in an analytical sample of 2097 persons (Fig. 1, bottom) (1323 young and 774 old participants at BL). Of the young, all the 1323 persons participated in the 6YFU. Of the old, 774 were re-examined in the 3 -year follow-up, and 575 participated in the 6YFU.

Slow walking speed (Seeman et al. 1994): Respondents who considered themselves to be normal or fast walkers were requested to walk a distance of 6 meters; 


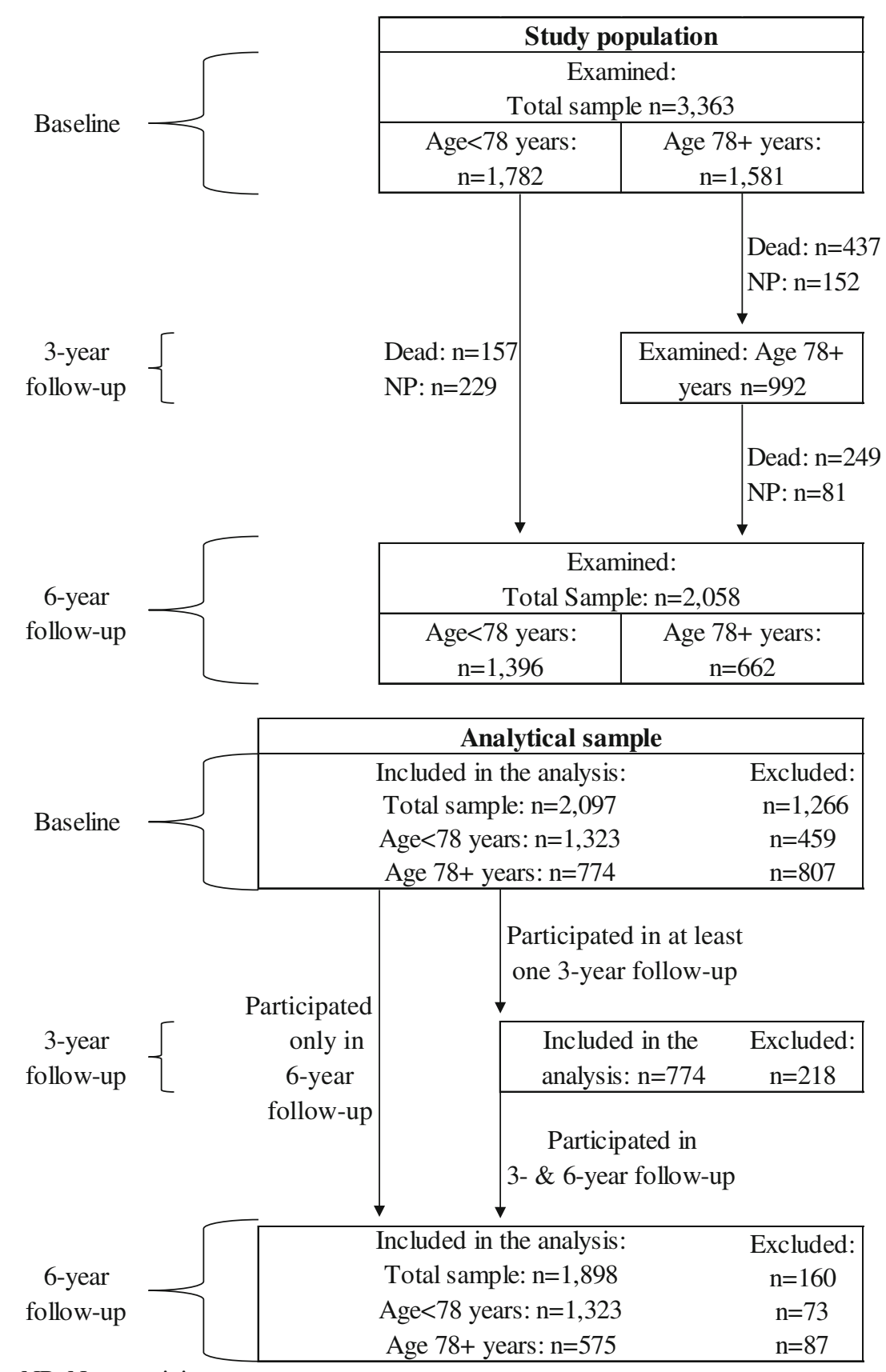

NP: Non-participants

Fig. 1 Study population and analytical sample. Source SNAC-K data 2004-2010, own calculations 


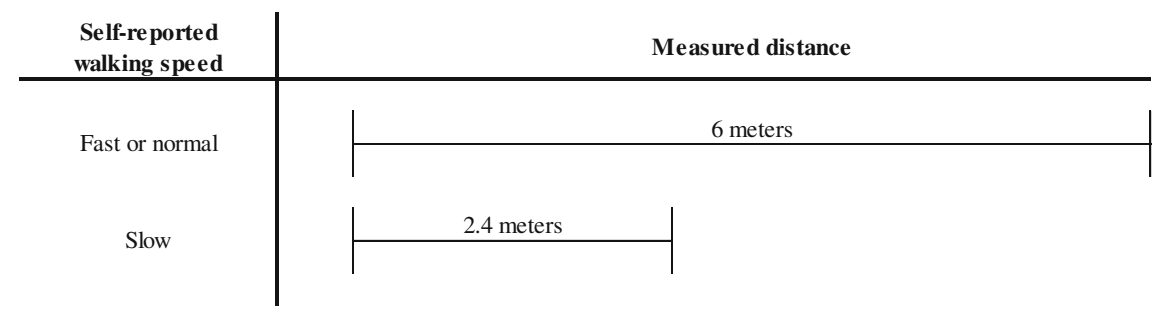

Fig. 2 Measurement of walking speed

otherwise, they walked $2.4 \mathrm{~m}$. Previous studies demonstrated that walking speed measured over the distances 2.4 and $6 \mathrm{~m}$ are comparable (Bohannon 2008). Time was measured in seconds (Fig. 2). We divided the sample into fast and slow walkers using the median (Total: $1 \mathrm{~m} / \mathrm{s}$; men: $1 \mathrm{~m} / \mathrm{s}$; women $0.85 \mathrm{~m} / \mathrm{s}$ ).

Change in walking speed: The change was measured between the follow-up and the previous wave. Those with a walking speed decrease of more than one standard deviation (as compared to the baseline walking speed) were defined as having experienced a decline.

Family Situation: In a first step we distinguished two characteristics of the current family situation: (1) living with a partner or not in the same household, and (2) having children or not (at least one child). In a second step, we combined this information to distinguish four groups: (1) childless, no partner; (2) childless, in partnership; (3) children, no partner; (4) children, in partnership. We did not differentiate by the number of children because of small numbers.

Control variables: We included socio-demographic characteristics such as age, sex, type of residence (private household versus nursing home); a pre-constructed index of socio-economic status which combined information about income, education as years of formal schooling, and blue/white collar occupation. In addition, we controlled for walking speed at baseline (less than one SD from the average), and the follow-up time (3-year and 6-year) in the Level and Change Models, expressed as an indicator variable at the two follow-up occasions.

Covariates: We included important life-style and health characteristics. Body mass index with $\mathrm{BMI} \leq 25$ : normal/underweight, $>25-30$ : overweight, $>30$ : obesity (Launer and Harris 1996). We combined normal and underweight into one group due to the low number of cases of underweight participants.

Alcohol consumption: we distinguished the categories no/occasional consumption, light-to-moderate drinking (1-14 drinks per week for men or 1-7 drinks per week for women), and heavy drinking ( $\geq=15$ drinks per week for men or $>=8$ drinks per week for women) (Jarvenpaa et al. 2005).

Physical activities: we used the questions about medium physical activity and combined them into the four categories daily, weekly/monthly, rarely/never, not specified (Rydwik et al. 2013).

The number of chronic diseases: chronic diseases were diagnosed by a physician on the basis of clinical examination and patient history. A disease was defined as 
chronic if it was of prolonged duration, left residual disability, worsened quality of life, or required a long period of care, treatment, or rehabilitation (Calderon-Larranaga et al. 2016).

Depression: we selected three items from the Montgomery-Åsberg Depression Rating Scale (Montgomery and Asberg 1979) and combined them into one variable indicating the presence of sadness, pessimistic thoughts, and feelings of loneliness.

\section{Modelling Strategy and Statistical Analysis}

We performed two types of GEE-regressions (Ziegler 2011) with binary outcome variables and logistic link functions. (1) In the "Level Models" we predicted slow walking speed in the follow-up by the characteristics of the previous wave. This implies that for individuals below age 78, all of whom had one follow-up after six years, only one outcome measurement was included in the model and that the characteristics from the BL were used as predictors of the walking speed in the 6YFU. People aged 78 and above in principle had two follow-ups, and the characteristics from the BL were used as predictors for walking speed in the $3 \mathrm{YFU}$, and the characteristics from the $3 \mathrm{YFU}$ were used as predictors for walking speed in the 6 YFU. Thus, each individual contributed a maximum of two outcome measurements and one outcome measurement in the case of death, attrition, or missing value. (2) In the "Change Models" we explored the decline in walking speed between two waves using the characteristics from the first of the two waves as predictors. Similar to above, characteristics from the BL were used to predict the change in walking speed for those below age 78 until the 6YFU, and they can only be included once in the model. For those aged 78 and above the characteristics of the BL predicted the change in walking speed by the $3 \mathrm{YFU}$, and the characteristics of the $3 \mathrm{YFU}$ predicted the change by the 6YFU, and they can be included in the model a maximum of two times. In both model types we used an indicator variable to account for the different length of the follow-up periods.

The within-person residual covariance matrix was evaluated with the unstructured correlation structure. To establish the gross-effect of the (change in) family position, we ran sex-specific models controlled for age, the respective design variables, and the walking speed at the previous wave. We refer to these models as Model 1. We then explored the interaction effect between the partnership and the child variables using the category childless, no partner as the reference category. We depict the gradient of the relationships in two figures. To explore possible interdependencies of the current family situation with other health characteristics, we introduced additional variables (Model 2: type of residence \& SES; Model 3: Model $2+$ BMI, alcohol consumption and physical activity; Model 4: Model $3+$ number of chronic morbidities, depression, Model 5: Model $4+$ alcohol consumption and physical activity + number of chronic morbidities, depression). All models were estimated separately for the two sexes. All calculations were performed in Stata 12.1, (StataCorp, TX, USA). 


\section{Results}

Slow walking speed (Table 1): Among those who were able to walk, walking speed at baseline ranged between 0.13 and $2 \mathrm{~m} / \mathrm{s}$, with a mean of $1.13 \mathrm{~m} / \mathrm{s}( \pm 0.36 \mathrm{~m} / \mathrm{s})$. We used this information as a control variable in both the Change and the Level Models. In the Level Models, walking speed ranged between 0 and $3 \mathrm{~m} / \mathrm{s}$ and the median was $1 \mathrm{~m} / \mathrm{s}$ : 1181 of the individuals were below the median and, thus, considered slow walkers. In the Change Models the mean change in walking speed was $-0.13 \mathrm{~m} / \mathrm{s}$ with a SD of $0.30 \mathrm{~m} / \mathrm{s}$ (median: $-0.12 \mathrm{~m} / \mathrm{s}) ; 512$ individuals $(20 \%)$ had a decline of more than one SD to the negative.

Family position (Table 2): For our main variable of interest, which is family position, as well as the other control variables, we explored the distributions at baseline (BL) and at the 3 YFU. At BL, about $15 \%$ of the respondents were childless without a partner, which increased to almost $18 \%$ in the $3 \mathrm{YFU}$. Only $5 \%$ at BL (3\% in the 3YFU) were childless and with a partner, while $35 \%$ (BL) and $42 \%$ (3YFU) had children but no partner. At BL, the vast majority (41\%) had children and was living with a partner, which decreased to $29 \%$ in the 3 YFU.

Covariates (Table 2): $64 \%$ (BL) of the respondents were female, which increased to $69 \%$ in the 3 YFU. Only about $1 \%$ was living in nursing homes $(3 \%$ in the 3 YFU). The vast majority had high SES (91\% BL, 85\% 3YFU), reflecting the highly socially selected population in Kungsholmen. Only $12 \%$ were obese, the vast majority had under/normal weight or were pre-obese. Only $22 \%$ were heavy drinkers (BL \& 3YFU), at BL 50\% were light-to-moderate drinker, in the $3 \mathrm{YFU}$ the majority were no/occasional drinkers. At BL, $46 \%$ rarely/never did any physical activity, in the 3 YFU this was $57 \%$. The respondents were rather healthy in terms of physical and mental health: $25 \%$ had no chronic diseases at BL (13\% at $3 \mathrm{YFU})$; the majority had one or two chronic diseases. At baseline, $50 \%$ had signs of depression, at the 3 YFU $53 \%$.

Table 1 Walking speed at baseline, and as outcome variables in the Level and Change Models

\begin{tabular}{|c|c|c|c|c|c|c|}
\hline \multicolumn{7}{|l|}{ Sample overview } \\
\hline $\begin{array}{l}\text { Walking speed } \\
\text { baseline (control } \\
\text { variable) }\end{array}$ & \multicolumn{3}{|c|}{ Outcome level models } & \multicolumn{3}{|c|}{ Outcome change models } \\
\hline $\begin{array}{l}\text { Min./max.: } \\
0.13-2 \mathrm{~m} / \mathrm{s}\end{array}$ & \multicolumn{3}{|c|}{ Min./max.: $0-3 \mathrm{~m} / \mathrm{s}$} & \multicolumn{3}{|c|}{ Min./max.: -1.39-1.01 m/s } \\
\hline $\begin{array}{l}\text { Mean/SD: } \\
1.13 \pm 0.36 \mathrm{~m} / \mathrm{s}\end{array}$ & \multicolumn{3}{|c|}{ Mean/SD: $0.95 \pm 0.40 \mathrm{~m} / \mathrm{s}$} & \multicolumn{3}{|c|}{ Mean/SD: $-0.13 \pm 0.30 \mathrm{~m} / \mathrm{s}$} \\
\hline \multirow[t]{2}{*}{ Median: $1.2 \mathrm{~m} / \mathrm{s}$} & \multicolumn{2}{|c|}{ Median: $1 \mathrm{~m} / \mathrm{s}$} & & \multicolumn{2}{|c|}{ Median: $-0.12 \mathrm{~m} / \mathrm{s}$} & \\
\hline & & $\mathrm{N}$ & $\%$ & & $\mathrm{~N}$ & $\%$ \\
\hline \multirow{2}{*}{$\begin{array}{l}\text { Outcome } \\
\text { binary-coded }\end{array}$} & $\geq$ Median & 1372 & 53.74 & Decline $>1 \mathrm{SD}$ & 2041 & 79.95 \\
\hline & $<$ Median & 1181 & 46.26 & Decline $\leq 1 \mathrm{SD}$ & 512 & 20.05 \\
\hline Total & & 2553 & 100.00 & & 2553 & 100.00 \\
\hline
\end{tabular}


Table 2 Characteristics of the analysis population

\begin{tabular}{|c|c|c|c|c|c|}
\hline \multirow[t]{2}{*}{ Variable } & \multirow[t]{2}{*}{ Category } & \multicolumn{2}{|c|}{ Baseline } & \multicolumn{2}{|c|}{$\begin{array}{l}\text { 3-year } \\
\text { follow-up }\end{array}$} \\
\hline & & $\mathrm{N}$ & $\%$ & $\mathrm{~N}$ & $\%$ \\
\hline \multirow[t]{8}{*}{ Age groups } & 60 & 589 & 28.09 & - & - \\
\hline & 66 & 420 & 20.03 & - & - \\
\hline & 72 & 314 & 14.97 & - & - \\
\hline & 78 & 322 & 15.36 & - & - \\
\hline & 81 & 147 & 7.01 & 233 & 51.10 \\
\hline & 84 & 126 & 6.01 & 88 & 19.30 \\
\hline & 87 & 72 & 3.43 & 67 & 14.69 \\
\hline & $90+$ & 107 & 5.10 & 68 & 14.91 \\
\hline \multirow[t]{2}{*}{ Sex } & Male & 762 & 36.34 & 141 & 30.92 \\
\hline & Female & 1335 & 63.66 & 315 & 69.08 \\
\hline \multirow[t]{5}{*}{ Family position } & Childless, no partner & 314 & 14.97 & 80 & 17.54 \\
\hline & Childless, in partnership & 112 & 5.34 & 15 & 3.29 \\
\hline & Child(ren), no partner & 727 & 34.67 & 191 & 41.89 \\
\hline & $\begin{array}{l}\text { Child(ren), in } \\
\text { partnership }\end{array}$ & 854 & 40.72 & 130 & 28.51 \\
\hline & Not specified & 90 & 4.29 & 40 & 8.77 \\
\hline \multirow[t]{2}{*}{ Type of residence } & Tenant/owner & 2068 & 98.62 & 442 & 96.93 \\
\hline & Residential care home & 29 & 1.38 & 14 & 3.07 \\
\hline \multirow[t]{3}{*}{ SES } & Low & 27 & 1.29 & 10 & 2.19 \\
\hline & Middle & 155 & 7.39 & 57 & 12.50 \\
\hline & High & 1915 & 91.32 & 389 & 85.31 \\
\hline \multirow[t]{4}{*}{ BMI } & Under-/normal weight & 917 & 43.73 & 159 & 34.87 \\
\hline & Pre-obesity & 867 & 41.34 & 150 & 32.89 \\
\hline & Obesity & 270 & 12.88 & 56 & 12.28 \\
\hline & Not specified & 43 & 2.05 & 91 & 19.96 \\
\hline \multirow[t]{3}{*}{ Alcohol } & No or occasional & 593 & 28.28 & 208 & 45.61 \\
\hline & Light-to-moderate & 1048 & 49.98 & 147 & 32.24 \\
\hline & Heavy drinking & 456 & 21.75 & 101 & 22.15 \\
\hline \multirow[t]{4}{*}{ Physical activity } & Daily & 116 & 5.53 & 24 & 5.26 \\
\hline & Weekly/monthly & 683 & 32.57 & 92 & 20.18 \\
\hline & Rarely/never & 959 & 45.73 & 261 & 57.24 \\
\hline & Not specified & 339 & 16.17 & 79 & 17.32 \\
\hline \multirow[t]{4}{*}{ Chronic diseases } & 0 & 528 & 25.18 & 60 & 13.16 \\
\hline & 1 & 631 & 30.09 & 119 & 26.10 \\
\hline & 2 & 456 & 21.75 & 130 & 28.51 \\
\hline & $3+$ & 482 & 22.99 & 147 & 32.24 \\
\hline \multirow[t]{2}{*}{ Depression } & No & 1046 & 49.88 & 240 & 52.63 \\
\hline & Yes & 1051 & 50.12 & 216 & 47.37 \\
\hline
\end{tabular}


Table 2 (continued)

\begin{tabular}{|c|c|c|c|c|c|}
\hline \multirow[t]{2}{*}{ Variable } & \multirow[t]{2}{*}{ Category } & \multicolumn{2}{|c|}{ Baseline } & \multicolumn{2}{|c|}{$\begin{array}{l}\text { 3-year } \\
\text { follow-up }\end{array}$} \\
\hline & & $\mathrm{N}$ & $\%$ & $\mathrm{~N}$ & $\%$ \\
\hline \multirow[t]{2}{*}{ Walking speed baseline } & $\begin{array}{l}>1 \text { SD from average in } \\
\text { the negative }\end{array}$ & 296 & 14.12 & 104 & 22.81 \\
\hline & $\begin{array}{l}\text { Less than } 1 \mathrm{SD} \text { or higher } \\
\text { than average }\end{array}$ & 1801 & 85.88 & 352 & 77.19 \\
\hline \multirow{2}{*}{$\begin{array}{l}\text { Duration between } \\
\text { predictor and outcome }\end{array}$} & 3 years & 720 & 34.33 & 456 & 100 \\
\hline & 6 years & 1377 & 65.67 & & \\
\hline Total & & 2097 & 100.00 & 456 & 100.00 \\
\hline
\end{tabular}

\section{Multivariate Analyses}

We first discuss the results from the Level Models, which explored the predictors of current slow walking speed. Model 1 shows the gross effect of the current family situation, Model 5 the effect corrected for confounding variables and covariates.

For both sexes combined, the presence of children significantly reduced the risk of slow walking speed but living with a partner did not have any statistically significant influence (Table 3). However, the latter result significantly depended on gender. Living in a partnership did not change the risk of slow walking speed for men (Table 3, Model 1 and Model 5), but appeared to be detrimental for the walking speed of women, particularly when controlled for other health related characteristics. Having children was associated with a lower likelihood of slow walking speed for both men and women, however the association was only significant for both sexes combined. (Model 1 and Model 5).

The interaction effect between partner and children confirmed the sex-specific results (Fig. 3). For men we found a clear negative gradient: the more family resources, the lower their risk of slow walking speed. The risk of slow walking speed was highest for the childless, living without a partner and it was lowest for those with children, living in a partnership; For women no clear and statistically significant gradient emerged, despite the larger sample size. Children tended to be beneficial, but living in a partnership tended to increase the risk of slow walking speed, counterbalancing the positive effect of children. The risk of slow walking speed was highest for the childless, living in a partnership.

Among men, SES and residency accounted for some but not all of the advantage of the partnered with children (Table 4: Model 2), but their advantage was attenuated when life-style (Table 4: Model 3) and morbidity information (Table 4: Model 4) were included. Among women no significant differences existed. The most pronounced tendency was the disadvantage of the childless women living in partnership. None of the confounding variables nor of the health related covariates could account for their particularly slow walking speed . 
Table 3 Odds ratios of logistic regression main effects models for partnership and children on the risk of slow walking speed (Level Models)

\begin{tabular}{|c|c|c|c|c|}
\hline \multirow[t]{2}{*}{ Characteristics } & \multicolumn{2}{|c|}{ Model 1} & \multicolumn{2}{|c|}{ Model 5} \\
\hline & OR & $\begin{array}{l}p \text { - } \\
\text { value }\end{array}$ & OR & $\begin{array}{l}p \text { - } \\
\text { value }\end{array}$ \\
\hline \multicolumn{5}{|l|}{ Total $^{\mathrm{a}}$} \\
\hline $\begin{array}{l}\text { In partnership (ref.: no } \\
\text { partner) }\end{array}$ & 0.98 & 0.88 & 1.13 & 0.38 \\
\hline Child (ref.: childless) & 0.73 & 0.03 & 0.73 & 0.04 \\
\hline \multicolumn{5}{|l|}{ Men } \\
\hline $\begin{array}{l}\text { In partnership (ref.: no } \\
\text { partner) }\end{array}$ & 0.73 & 0.16 & 0.82 & 0.41 \\
\hline Child (ref.: childless) & 0.64 & 0.09 & 0.74 & 0.35 \\
\hline \multicolumn{5}{|l|}{ Women } \\
\hline $\begin{array}{l}\text { In partnership (ref.: no } \\
\text { partner) }\end{array}$ & 1.22 & 0.24 & 1.42 & 0.05 \\
\hline Child (ref.: childless) & 0.81 & 0.23 & 0.79 & 0.19 \\
\hline
\end{tabular}

Model 1: controlled for age, design variables

Model 5: controlled for age, design variables, type of residence \& SES, BMI, alcohol consumption \& physical activity, number of chronic morbidities, depression

${ }^{\mathrm{a} C}$ Controlled for age, sex, design variables
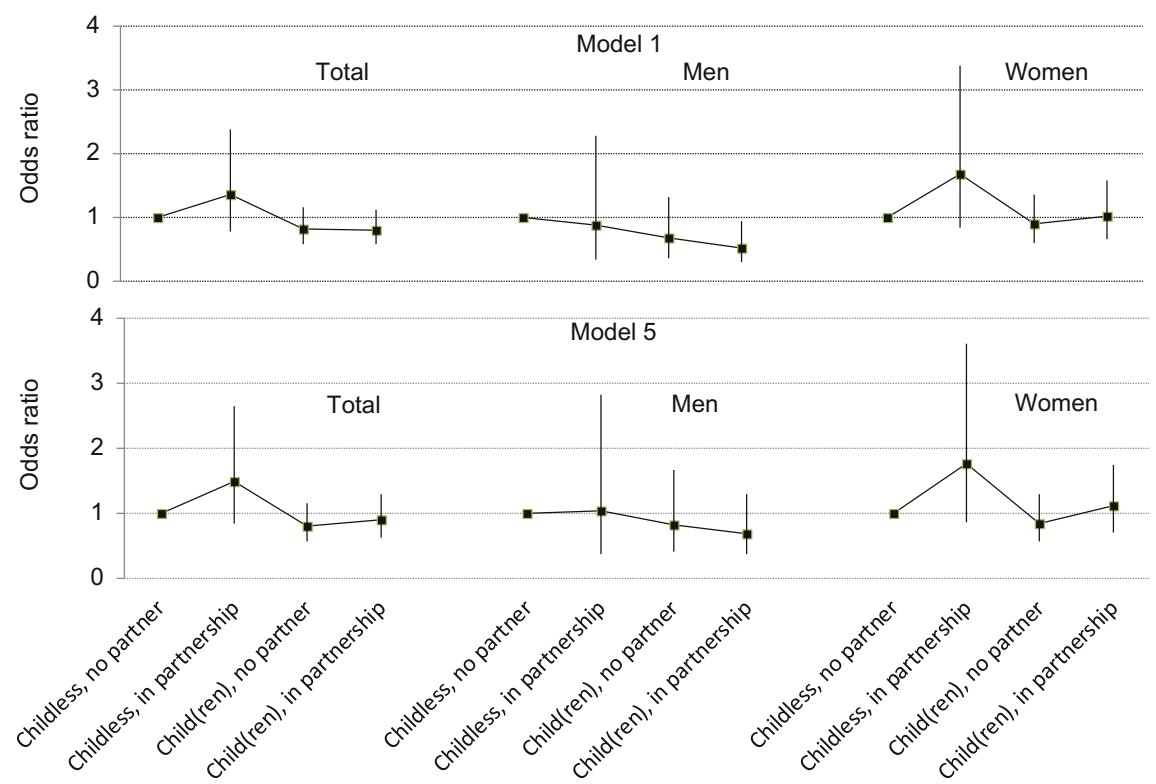

Fig. 3 Odds ratios of the interaction effect between partnership and parenthood in the Level Models: gross-effect (Model 1) and controlled for possible mediators (Model 5) 
Table 4 Odds ratios of family situation based on logistic regression models of poor walking speed (Level Models)

\begin{tabular}{|c|c|c|c|c|c|c|c|c|c|c|}
\hline \multirow[b]{2}{*}{ Characteristics } & \multicolumn{2}{|c|}{ Model 1} & \multicolumn{2}{|c|}{ Model 2} & \multicolumn{2}{|c|}{ Model 3} & \multicolumn{2}{|c|}{ Model 4} & \multicolumn{2}{|c|}{ Model 5} \\
\hline & OR & $\begin{array}{l}p \text { - } \\
\text { value }\end{array}$ & OR & $\begin{array}{l}p- \\
\text { value }\end{array}$ & OR & \begin{tabular}{|l|}
$p-$ \\
value
\end{tabular} & OR & $\begin{array}{l}p- \\
\text { value }\end{array}$ & OR & $\begin{array}{l}p- \\
\text { value }\end{array}$ \\
\hline \multicolumn{11}{|l|}{ Men } \\
\hline \multicolumn{11}{|c|}{ Family situation (ref.: Childless, no partner) } \\
\hline $\begin{array}{l}\text { Childless, in } \\
\text { partnership }\end{array}$ & 0.86 & 0.77 & 0.98 & 0.97 & 1.03 & 0.96 & 0.98 & 0.97 & 1.04 & 0.94 \\
\hline $\begin{array}{l}\text { Child(ren), no } \\
\text { partner }\end{array}$ & 0.68 & 0.25 & 0.75 & 0.40 & 0.82 & 0.56 & 0.77 & 0.46 & 0.83 & 0.60 \\
\hline $\begin{array}{l}\text { Child(ren), in } \\
\text { partnership }\end{array}$ & 0.52 & 0.03 & 0.60 & 0.08 & 0.63 & 0.14 & 0.64 & 0.15 & 0.69 & 0.25 \\
\hline Not specified & 0.27 & 0.04 & 0.17 & 0.02 & 0.24 & 0.05 & 0.19 & 0.03 & 0.27 & 0.09 \\
\hline \multicolumn{11}{|l|}{ Women } \\
\hline \multicolumn{11}{|c|}{ Family situation (ref.: Childless, no partner) } \\
\hline $\begin{array}{l}\text { Childless, in } \\
\text { partnership }\end{array}$ & 1.67 & 0.16 & 1.70 & 0.14 & 1.72 & 0.13 & 1.74 & 0.12 & 1.77 & 0.12 \\
\hline $\begin{array}{l}\text { Child(ren), no } \\
\text { partner }\end{array}$ & 0.90 & 0.59 & 0.89 & 0.57 & 0.88 & 0.53 & 0.86 & 0.47 & 0.85 & 0.44 \\
\hline $\begin{array}{l}\text { Child(ren), in } \\
\text { partnership }\end{array}$ & 1.01 & 0.96 & 1.02 & 0.92 & 1.05 & 0.84 & 1.08 & 0.73 & 1.11 & 0.65 \\
\hline Not specified & 0.66 & 0.21 & 0.65 & 0.20 & 0.62 & 0.16 & 0.65 & 0.21 & 0.62 & 0.17 \\
\hline
\end{tabular}

Model 1: family situation, age, design variables

Model 2: family situation, SES, type of residence, age, design variables

Model 3: family situation, SES, type of residence, BMI, alcohol consumption, physical activity, age, design variables

Model 4: family situation, SES, type of residence, number of chronic morbidities, depression, age, design variables

Model 5: family situation, SES, type of residence, BMI, alcohol consumption, physical activity, number of chronic morbidities, depression, age, design variables

To explore the effects of the covariates we turn to the models for both sexes combined (not shown). We observed that women had a significantly higher risk of low walking speed than men, however, this difference was fully explained by life-style and health characteristics. The effects of the other covariates were generally as expected: Those living in residential care units had a higher risk of slow walking, which was largely explained by life-style and health variables. SES exerted a strong effect, which was partly attributable to life-style factors. Light-to-moderate alcohol drinking seemed to be positively related to walking speed; rarely/never performing any physical activity severely increased the risk of slow walking speed. High numbers of chronic morbidities increased the risk of slow walking speed as did signs of depression. As expected, walking speed in the previous wave was a strong predictor of current walking speed.

Turning to the Change Models, which explored the risk of a severely declining walking speed, for men we found little effect of living in a partnership, and a 
Table 5 Odds ratios of logistic regression main effects models for partnership and children on the risk of poor walking speed (Change Models)

\begin{tabular}{|c|c|c|c|c|}
\hline \multirow[t]{2}{*}{ Characteristics } & \multicolumn{2}{|c|}{ Model 1} & \multicolumn{2}{|c|}{ Model 5} \\
\hline & OR & \begin{tabular}{|l|}
$p-$ \\
value
\end{tabular} & OR & \begin{tabular}{|l|}
$p-$ \\
value
\end{tabular} \\
\hline \multicolumn{5}{|l|}{ Total $^{\mathrm{a}}$} \\
\hline $\begin{array}{l}\text { In partnership (ref.: no } \\
\text { partner) }\end{array}$ & 1.01 & 0.94 & 1.11 & 0.40 \\
\hline Child (ref.: childless) & 0.83 & 0.14 & 0.84 & 0.16 \\
\hline \multicolumn{5}{|l|}{ Men } \\
\hline $\begin{array}{l}\text { In partnership (ref.: no } \\
\text { partner) }\end{array}$ & 1.02 & 0.92 & 1.00 & 1.00 \\
\hline Child (ref.: childless) & 0.61 & 0.03 & 0.64 & 0.06 \\
\hline \multicolumn{5}{|l|}{ Women } \\
\hline $\begin{array}{l}\text { In partnership (ref.: no } \\
\text { partner) }\end{array}$ & 1.00 & 0.98 & 1.16 & 0.35 \\
\hline Child (ref.: childless) & 0.92 & 0.60 & 0.92 & 0.61 \\
\hline
\end{tabular}

Model 1: controlled for age, design variables

Model 5: controlled for SES, type of residence, BMI, alcohol consumption, physical activity, number of chronic morbidities, depression, age, design variables

${ }^{\mathrm{a} C}$ Controlled for sex

positive effect of having children (Table 5). This positive effect was not explained by the covariates. For women, the risk of severely declining walking speed was not related to living in a partnership, nor to having children.

The interaction effect between partnership and parenthood (Fig. 4) revealed that for both sexes the childless, living in a partnership had the highest risk of a severe decline, however, none of the differences were statistically significant. The presence of children, independent of the form of partnership, tended to be beneficial only for men.

Severe declines in walking speed are predominantly influenced by the characteristics related to poor physical health (Table 6).

\section{Discussion}

Among the elderly, the family situation at old age significantly predicts health in terms of slow walking speed; the relationship with changes in health, measured as severe declines in walking speed, is less clear. While much of the relationship is gender specific there are also common patterns. Among both sexes, having no children is related to slow walking speed albeit the effect is only statistically significant for men. In addition, childless persons living in a partnership showed the steepest decline in walking speed. We will return to this later. 

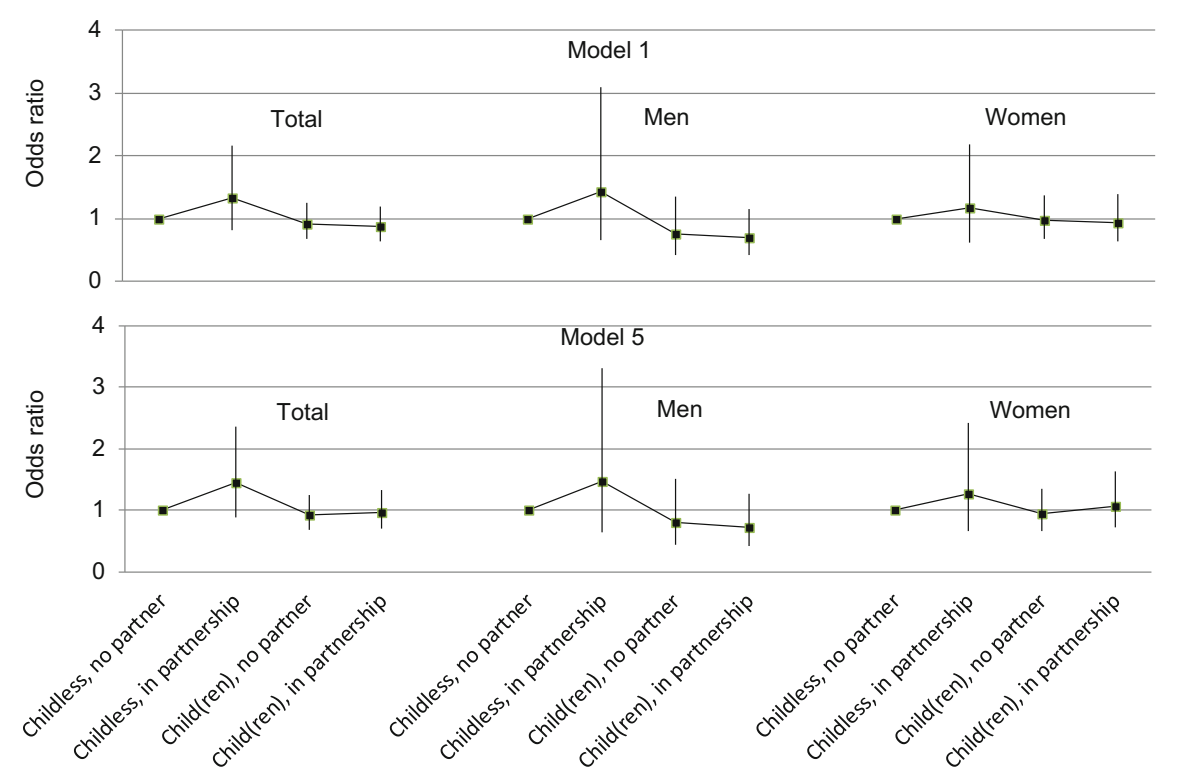

Fig. 4 Odds ratios of the interaction effect between partnership and parenthood in the Change Models: gross-effect (Model 1) and controlled for possible mediators (Model 5)

Using the slowest $25 \%$ quartile to define slow walking speed, we found that the pattern of the results did not change and differences by family situation even increased. However, when exploring walking speed in a linear mixed model we found that there was no relationship with family situation (not shown). This suggests that in general walking speed is only loosely related to family situation but that sub-performance and extreme deficiencies in walking speed may be also routed in the family environment.

Living in a partnership tends to be beneficial only for men, for women it may even be detrimental when controlled for life-style and health characteristics. For men there is a clear positive gradient between the amount of family resources and walking speed: the childless living alone have the slowest walking speed, those living in a partnership and who have children have the highest. Life-style factors such as obesity, smoking, and alcohol consumption mediate the advantage of the latter group. This is also true for health related characteristics such as the number of morbidities and signs of depression. For women, no positive gradient exists. On the contrary, living in a partnership exerts a negative effect, both among the childless and among those with children. Thus, for men we can confirm our initial hypothesis that higher amounts of family resources positively influence walking speed, for women we have to reject it; the effect of children appears to be positive, the effect of a partner, however, is negative.

It is difficult to disentangle the effects of health selection and causal factors related to protective or detrimental effects of the current family situation. Both 
Table 6 Odds ratios of logistic regression models of the risk of severe decline in walking speed (Change Models)

\begin{tabular}{|c|c|c|c|c|c|c|c|c|c|c|}
\hline \multirow[b]{2}{*}{ Characteristics } & \multicolumn{2}{|c|}{ Model 1} & \multicolumn{2}{|c|}{ Model 2} & \multicolumn{2}{|c|}{ Model 3} & \multicolumn{2}{|c|}{ Model 4} & \multicolumn{2}{|c|}{ Model 5} \\
\hline & OR & \begin{tabular}{|l|}
$p-$ \\
value
\end{tabular} & OR & $\begin{array}{l}p- \\
\text { value }\end{array}$ & OR & \begin{tabular}{|l|}
$p-$ \\
value
\end{tabular} & OR & $\begin{array}{l}p- \\
\text { value }\end{array}$ & OR & $\begin{array}{l}p- \\
\text { value }\end{array}$ \\
\hline \multicolumn{11}{|l|}{ Men } \\
\hline \multicolumn{11}{|c|}{ Family situation (ref.: Childless, no partner) } \\
\hline $\begin{array}{l}\text { Childless, in } \\
\text { partnership }\end{array}$ & 1.43 & 0.37 & 1.53 & 0.29 & 1.48 & 0.33 & 1.53 & 0.30 & 1.47 & 0.36 \\
\hline $\begin{array}{l}\text { Child(ren), no } \\
\text { partner }\end{array}$ & 0.75 & 0.34 & 0.79 & 0.45 & 0.78 & 0.43 & 0.82 & 0.53 & 0.81 & 0.50 \\
\hline $\begin{array}{l}\text { Child(ren), in } \\
\text { partnership }\end{array}$ & 0.69 & 0.16 & 0.75 & 0.28 & 0.73 & 0.25 & 0.74 & 0.29 & 0.72 & 0.26 \\
\hline Not specified & 0.45 & 0.21 & 0.43 & 0.18 & 0.44 & 0.21 & 0.48 & 0.25 & 0.49 & 0.27 \\
\hline \multicolumn{11}{|c|}{ Women } \\
\hline \multicolumn{11}{|c|}{ Family situation (ref.: Childless, no partner) } \\
\hline $\begin{array}{l}\text { Childless, in } \\
\text { partnership }\end{array}$ & 1.16 & 0.64 & 1.15 & 0.67 & 1.18 & 0.62 & 1.23 & 0.52 & 1.28 & 0.46 \\
\hline $\begin{array}{l}\text { Child(ren), no } \\
\text { partner }\end{array}$ & 0.97 & 0.85 & 0.94 & 0.75 & 0.96 & 0.82 & 0.93 & 0.68 & 0.95 & 0.79 \\
\hline $\begin{array}{l}\text { Child(ren), in } \\
\text { partnership }\end{array}$ & 0.93 & 0.73 & 0.93 & 0.70 & 0.98 & 0.93 & 1.02 & 0.93 & 1.08 & 0.72 \\
\hline Not specified & 0.99 & 0.97 & 0.98 & 0.95 & 0.91 & 0.75 & 0.97 & 0.91 & 0.90 & 0.73 \\
\hline
\end{tabular}

Model 1: family situation, age, design variables

Model 2: family situation, SES, type of residence, age, design variables

Model 3: family situation, SES, type of residence, BMI, alcohol consumption, physical activity, age, design variables

Model 4: family situation, SES, type of residence, number of chronic morbidities, depression, age, design variables

Model 5: family situation, SES, type of residence, BMI, alcohol consumption, physical activity, number of chronic morbidities, depression, age, design variables

genders over their whole life course might be strongly health selected into partnership and parenthood. We observed family status at old age, and our categories of current family situation do not necessarily reflect the life-long partnership biography. In particular, those currently living without a partner comprise the never-married, as well as the separated, divorced, or widowed and very different health selection forces have acted on these groups. It is thus highly unlikely that the patterns observed purely reflect these selection processes. On the contrary, for men the strong positive gradient points towards protective effects of having a partner and children who, in addition to their influence on life-style, are also important resources of help and care provision. For elderly women the story is more complex. While living with a partner may be beneficial in terms of emotional support and general resources related to health and well-being, a partner can also be the source of a large burden when his health fails. In Sweden, as in other welfare states with less generous old-age care provision, women are more likely than men to provide 
personal care in combination with a variety of other caring tasks. Men, on the contrary, are more likely to provide some kind of practical help for a mother or a neighbour/friend (Jegermalm 2006). At the same time Swedish caregivers have worse perceptions concerning self-rated health, psychological wellbeing, and reporting days of poor health in the last month (Berglund et al. 2015). Thus, after the death of a partner, women are released from an immense burden and face a new life situation in which they have to be more self-reliant. As a consequence, they may stay more active, which has a positive impact on their walking speed. However, it was also reported that the well-being of a caregiving spouse was consistently compromised at every stage of the caregiving career, even after the death of the partner (Rafnsson et al. 2015).

Gender specific family roles related to physical fitness may also have detrimental effects on the walking speed of women. Von der Lippe and Rattay found that divorced women were physically more active than married women, and that mothers were the least active, however, little is known whether this also extends into old age. Given the gender specific distribution of unpaid work in families described in the chapter by Oláh, Kotowska and Richter, one would expect that during much of their life course women simply have less time available to spend on physical activity. In addition gender specific preferences of time use have been observed repeatedly: Time use surveys show that elderly men use more of their time for physical activity, while women are more heavily engaged in social activities (Finkel et al. 2016).

While children appear to be associated with faster walking speed among both genders, this effect is not significant for women, while it remains significant for men even after control for life-style and health related variables. Because of the small numbers we were not able to explore the effect by number of children; however, the lack of significance among women may indicate a u-shaped pattern, as found in other studies. Tomassini, Di Gessa, and Egidi describe in their chapter that health is best for mothers of one to two children, and starts to deteriorate for three and more children. This is true in the Italian context of a familialistic welfare state as well as in other countries, such as e.g. the Nordic dual-earner welfare states (for a definition of welfare state see the chapter of Oláh, Kotowska and Richter). The increasing risk posed by a higher number of children is related mainly to cardiovascular disease, as pointed out by Hank and Steinbach in their chapter. On the contrary, for men, the risk of poor health and high mortality decreases continuously with an increasing number of children. Over the life course men's health behavior is less related to the presence of children than is women's (see the chapter of von der Lippe and Rattay), which might be negative in terms of smoking and at risk-alcohol consumption but positive in terms of physical activity. In addition women may face a biological toll of repeated pregnancy (Peters et al. 2016). Children are important care providers for parents of both genders; in case of providing care to fathers they are, however, usually secondary providers, whereas in case of providing care to mothers they often become the primary care provider due to the higher mortality of men at old age. Thus for fathers, children may indeed be an additional care resource, for mothers they may partly take over care work of the partners. 
Among both genders, the largest accelerated decline in walking speed was found in the childless living with a partner. In the cohorts observed in this study, childlessness while living in a partnership is a rather rare phenomenon, with only five percent of the elderly belonging to this group at the baseline wave of the SNAC-K. Health selection into childlessness may therefore play an important role and may explain the accelerated speed of health deterioration. This explanation is supported by the fact that neither control for life-style factors nor for physical and mental health can explain the accelerated decline in walking speed.

Hank and Steinbach pointed out in their chapter that current family status was correlated mainly with mental health, while the family biography was related mainly to slowly developing chronic health conditions. In our study we controlled for depression in terms of feelings of sadness and loneliness, in addition to multi-morbidity which attenuated the health advantage of the partnered men with children. This leads us to conclude that current family status, in addition to the family biography, may also be an important predictor of physical health.

It is noteworthy to point out that, at middle ages, women's health is more affected by family status than men's (see the chapters of Doblhammer and Gumà, and Georges, Kreft and Doblhammer) while at old age the opposite is true. At middle ages women not living in a marriage who have children, particularly single mothers, are severely disadvantaged in their subjective health. As Doblhammer and Gumà showed, much of this disadvantage can be explained by financial deprivation. For middle-aged men, differences in their family situation are much smaller and financial deprivation even works the other way; married men with children seem to face financial difficulties more often. At old age men profit from partnership in terms of health, women do not. In our study population financial difficulties cannot explain the differences because the SNAC-K population is highly selected in social terms and generally does not experience financial problems. SES does only account for a small proportion of the health differences by family status.

In our study we cannot disentangle the effect of the partnership biography from the effect of the current family status due to the lack of biographical information in the SNAC-K data. These data also lack information on the health situation of the partner, which prevents us from testing whether the partner's health is an important mediating factor. Another weakness is the highly selected study population in terms of health and social status. This bias may have introduced an underestimation of the effect of the current family situation on health. Because highly educated women may be less dependent on their partners in many ways, including in financial terms, this may also explain the lack of a positive effect of a partner on their health. On the other hand it may also dampen the negative effect of a partner's ill health because older persons with lower education increasingly receive family care, while those with higher education are more likely to purchase and use private services (Szebehely and Trydegard 2012).

Another possible limitation is that non-married people without children may be less likely to survive to participate in the follow-up examination. This may lead to an underestimation of the associations (Koskinen et al. 2007). 
Finally, the use of different distances in the test of walking speed may be a potential limitation. However, studies support the view that tests for walking speed are generally considered to be highly reliable, regardless of the distance (Seeman et al. 1994).

The main strength of this study lies in its longitudinal design focused on a large sample of largely community-based elderly. The panel character of the study permitted us to measure the current family situation as a predictor of health which was observed prior to the health outcome, thus avoiding the problem of reverse causation. Moreover, we use an objective measure of walking speed measured by qualified health care professionals, which is also true for the other characteristics related to physical and mental health.

Our study demonstrated that the family situation is an important determinant of the health of individuals. Its influence changes over the life course and differs for men and women. In the future, changing family biographies will also lead to new partnership forms at old age, a phenomenon which so far is only emerging at young and middle-ages. Based on our results we may speculate that living in consensual unions or living together apart may have a negative impact on the health of elderly men because their partners may be less committed to provide care in case of poor health. This, however, may improve the health of elderly women who are released from the burden of providing care. Future studies will tell.

\section{Conclusion}

In ageing societies new policies have to be developed to meet the increasing demand for care by expanding the formal care sector in combination with strengthening informal care arrangements. Most importantly, it is necessary to identify those vulnerable groups which need support from both sectors. We have shown that men and women without children may need more support from formal caregivers, not only because of the lack of family members who could provide informal care but also because they suffer from comparably worse health. While partners are important informal care providers to each other, older women living with someone may also have an increased need of societal support. They carry much of the informal care burden at old age, quite often compromising their own health and increasing their own care demand.

\section{References}

Atkinson, H. H., Rosano, C., Simonsick, E. M., Williamson, J. D., Davis, C, Ambrosius, W. T., et al. (2007). Cognitive function, gait speed decline, and comorbidities: The health, aging and body composition study. The Journals of gerontology. Series A, Biological Sciences and Medical Sciences, 62(8), S. 844-S. 850. 
Berglund, E., Lytsy, P., \& Westerling, R. (2015). Health and wellbeing in informal caregivers and non-caregivers: A comparative cross-sectional study of the Swedish general population. Health and Quality of Life Outcomes, 13, S. 109. https://doi.org/10.1186/s12955-015-0309-2.

Bergman, H., Ferrucci, L., Guralnik, J., Hogan, D. B., Hummel, S., Karunananthan, S., et al. (2007). Frailty: an emerging research and clinical paradigm-issues and controversies. The Journals of Gerontology. Series A, Biological Sciences and Medical Sciences, 62(7), S. 731-S. 737.

Bohannon, R. W. (2008). Population representative gait speed and its determinants. Journal of Geriatric Physical Therapy (2001) 31 (2), S. 49-S. 52.

Calderon-Larranaga, A., Vetrano, D. L., Onder, G., Gimeno-Feliu, L. A., Coscollar-Santaliestra, C., Carfi, A., et al. (2016). Assessing and measuring chronic multimorbidity in the older population: A proposal for its operationalization. The Journals of Gerontology. Series A, Biological Sciences and Medical Sciences. https://doi.org/10.1093/gerona/glw233.

Cooper, R., Strand, B. H., Hardy, R., Patel, K. V., \& Kuh, D. (2014). Physical capability in mid-life and survival over 13 years of follow-up: British birth cohort study. BMJ (Clinical Research Ed.), 348, g2219. https://doi.org/10.1136/bmj.g2219.

Elbaz, A., Sabia, S., Brunner, E., Shipley, M., Marmot, M., Kivimaki, M., et al. (2013): Association of walking speed in late midlife with mortality: Results from the Whitehall II cohort study. Age (Dordrecht, Netherlands), 35(3), S. 943-S. 952. https://doi.org/10.1007/ s11357-012-9387-9.

Finkel, D., Andel, R., \& Pedersen, N. L. (2016). Gender differences in longitudinal trajectories of change in physical, social, and cognitive/sedentary leisure activities. The Journals of Gerontology. Series B, Psychological Sciences and Social Sciences. https://doi.org/10.1093/ geronb/gbw116.

Jarvenpaa, T., Rinne, J. O., Koskenvuo, M., Raiha, I., \& Kaprio, J. (2005). Binge drinking in midlife and dementia risk. Epidemiology (Cambridge, Mass.), 16(6), S. 766-S. 771.

Jegermalm, M. (2006). Informal care in Sweden. A typology of care and caregivers. International Journal of Social Welfare, 15(4), S. 332-S. 343. https://doi.org/10.1111/j.1468-2397.2006. 00400.x.

Koskinen, S., Joutsenniemi, K., Martelin, T., \& Martikainen, P. (2007). Mortality differences according to living arrangements. International Journal of Epidemiology, 36(6), S. 1255-S. 1264. https://doi.org/10.1093/ije/dym212.

Lagergren, M., Fratiglioni, L., Hallberg, I. R., Berglund, J., Elmstahl, S., Hagberg, B., et al. (2004). A longitudinal study integrating population, care and social services data. The Swedish National study on Aging and Care (SNAC). In: Aging Clinical and Experimental Research, 16 (2), S. 158-S. 168.

Launer, L. J., \& Harris, T. (1996). Weight, height and body mass index distributions in geographically and ethnically diverse samples of older persons. Ad Hoc committee on the statistics of anthropometry and aging. Age and Ageing, 25(4), S. 300-S. 306.

Montgomery, S. A., \& Asberg, M. (1979). A new depression scale designed to be sensitive to change. The British Journal of Psychiatry: The Journal of Mental Science, 134, S. 382-S. 389.

Peters, S. A., Yang, L., Guo, Y., Chen, Y., Bian, Z., Millwood, I. Y., et al. (2016). Parenthood and the risk of cardiovascular diseases among 0.5 million men and women: Findings from the China Kadoorie Biobank. International Journal of Epidemiology. https://doi.org/10.1093/ije/ dyw144.

Rafnsson, S. B., Shankar, A., \& Steptoe, A. (2015). Informal caregiving transitions, subjective well-being and depressed mood: Findings from the english longitudinal study of ageing. Aging \& Mental Health, S. 1-S. 9. https://doi.org/10.1080/13607863.2015.1088510.

Revenson, T. A., Griva, K., Luszczynska, A., Morrison, V., Panagopoulou, E., Vilchinsky, N., et al. (2015). Gender and caregiving: The costs of caregiving for women. In T. A. Revenson, K. Griva, A. Luszczynska, V. Morrison, E. Panagopoulou, N. Vilchinsky, \& M. Hagedoorn (Eds.), Caregiving in the illness context (pp. S. 48-S. 63). Basingstoke: Palgrave Pivot.

Rydwik, E., Welmer, A.-K., Kareholt, I., Angleman, S., Fratiglioni, L., \& Wang, H.-X. (2013). Adherence to physical exercise recommendations in people over 65-the SNAC-Kungsholmen 
study. European Journal of Public Health, 23(5), S. 799-S. 804. https://doi.org/10.1093/ eurpub/cks150.

Seeman, T. E., Charpentier, P. A., Berkman, L. F., Tinetti, M. E., Guralnik, J. M., Albert, M., et al. (1994). Predicting changes in physical performance in a high-functioning elderly cohort. MacArthur studies of successful aging. Journal of Gerontology, 49(3), M97-M108. https://doi. org/10.1093/geronj/49.3.M97.

Studenski, S., Perera, S., Patel, K., Rosano, C., Faulkner, K., Inzitari, M., et al. (2011). Gait speed and survival in older adults. JAMA, 305(1), S. 50-S. 58. https://doi.org/10.1001/jama.2010. 1923.

Szebehely, M., \& Trydegard, G.-B. (2012). Home care for older people in Sweden: a universal model in transition. Health and Social Care in the Community, 20(3), S. 300-S. 309. https:// doi.org/10.1111/j.1365-2524.2011.01046.x.

Weber, D. (2016). Differences in physical aging measured by walking speed: Evidence from the english longitudinal study of ageing. BMC Geriatrics, 16, S. 31. https://doi.org/10.1186/ s12877-016-0201-x.

Welmer, A.-K., Kareholt, I., Rydwik, E., Angleman, S., \& Wang, H.-X. (2013). Education-related differences in physical performance after age 60: A cross-sectional study assessing variation by age, gender and occupation. BMC Public Health, 13, S. 641. https://doi.org/10.1186/14712458-13-641.

Welmer, A.-K., Rizzuto, D., Laukka, E. J., Johnell, K., \& Fratiglioni, L. (2016). Cognitive and physical function in relation to the risk of injurious falls in older adults: A population-based study. The Journals of Gerontology. Series A, Biological Sciences and Medical Sciences. https://doi.org/10.1093/gerona/glw141.

Welmer, A.-K., Rizzuto, D., Qiu, C., Caracciolo, B., \& Laukka, E. J. (2014). Walking speed, processing speed, and dementia: A population-based longitudinal study. The Journals of Gerontology. Series A, Biological Sciences and Medical Sciences, 69(12), S. 1503-S. 1510. https://doi.org/10.1093/gerona/glu047.

Ziegler, A. (2011). Generalized estimating equations. New York, NY: Springer (Lecture Notes in Statistics, 204). Online verfügbar unter http://dx.doi.org/10.1007/978-1-4614-0499-6.

Open Access This chapter is licensed under the terms of the Creative Commons Attribution 4.0 International License (http://creativecommons.org/licenses/by/4.0/), which permits use, sharing, adaptation, distribution and reproduction in any medium or format, as long as you give appropriate credit to the original author(s) and the source, provide a link to the Creative Commons license and indicate if changes were made.

The images or other third party material in this chapter are included in the chapter's Creative Commons license, unless indicated otherwise in a credit line to the material. If material is not included in the chapter's Creative Commons license and your intended use is not permitted by statutory regulation or exceeds the permitted use, you will need to obtain permission directly from the copyright holder. 